\title{
Relationship between petal abscission and programmed cell death in Prunus yedoensis and Delphinium belladonna
}

\author{
Tetsuya Yamada $\cdot$ Kazuo Ichimura • \\ Wouter G. van Doorn
}

Received: 2 March 2007 / Accepted: 25 May 2007 / Published online: 6 July 2007

(C) Springer-Verlag 2007

\begin{abstract}
Depending on the species, the end of flower life span is characterized by petal wilting or by abscission of petals that are still fully turgid. Wilting at the end of petal life is due to programmed cell death (PCD). It is not known whether the abscission of turgid petals is preceded by PCD. We studied some parameters that indicate PCD: chromatin condensation, a decrease in nuclear diameter, DNA fragmentation, and DNA content per nucleus, using Prunus yedoensis and Delphinium belladonna which both show abscission of turgid petals at the end of floral life. No DNA degradation, no chromatin condensation, and no change in nuclear volume was observed in $P$. yedoensis petals, prior to abscission. In abscising D. belladonna petals, in contrast, considerable DNA degradation was found, chromatin was condensed and the nuclear volume considerably reduced. Following abscission, the nuclear area in both species drastically increased, and the chromatin became unevenly distributed. Similar chromatin changes were observed after dehydration $\left(24 \mathrm{~h}\right.$ at $\left.60^{\circ} \mathrm{C}\right)$ of petals severed at the time of flower opening, and in dehydrated petals of Ipomoea nil and Petunia hybrida, severed at the time of flower opening. In these flowers the petal life span is terminated by wilting
\end{abstract}

T. Yamada $\cdot$ K. Ichimura

National Institute of Floricultural Science,

305-8519 Ibaraki, Japan

W. G. van Doorn $(\bowtie)$

Wageningen University and Research Centre, 6700 AA Wageningen, The Netherlands

e-mail: wouter.vandoorn@wur.nl

Present Address:

T. Yamada

Tokyo University of Agriculture and Technology,

183-8509 Tokyo, Japan rather than abscission. It is concluded that the abscission of turgid petals in D. belladonna was preceded by a number of PCD indicators, whereas no such evidence for PCD was found at the time of $P$. yedoensis petal abscission. Dehydration of the petal cells, after abscission, was associated with a remarkable nuclear morphology which was also found in younger petals subjected to dehydration. This nuclear morphology has apparently not been described previously, for any organism.

Keywords Abscission - DNA degradation · Flow cytometry $\cdot$ Petal senescence $\cdot$ Programmed cell death . Wilting
Abbreviations
DAPI 4,6-Diamidino-2-phenylindole
PCD Programmed cell death

\section{Introduction}

Floral life span depends on the fate of the petals. In several species the end of floral life span is due to petal withering or wilting. The petals in most of these species desiccate, and finally abscise or fall due to growth of the fruit. Only in a few species the desiccated petals remain attached to the fruit. In another large group of species the end of floral life span is determined by abscission of petals that are mostly or fully turgid.

Wilting in petals, at the end of their lifespan, is due to a series of highly regulated processes that lead to cell death, thus is a form of programmed cell death (PCD; van Doorn et al. 2003). Prior to visible PCD, many macromolecules in the petal cells are degraded to molecules that are suitable for phloem transport. These mobile molecules are 
transported to other parts of the plant (Winkenbach et al. 1970a, b). Typical for PCD in wilting petals is the disappearance of most of the organelles and accumulation of degrading enzymes in the vacuole. This is followed by rupture of the vacuolar membrane, whereby several hydrolases are released. Tonoplast rupture in numerous cells results in their collapse, which is visible as wilting (Winkenbach 1970a, b; van Doorn et al. 2003). PCD in several plant parts (Gunawardena et al. 2001; Wojciechowska and Olszewska 2003), including petals, is also usually accompanied by DNA degradation (van der Kop et al. 2003; Wagstaff et al. 2003; Yamada et al. 2006a, b) and chromatin condensation (Yamada et al. 2006a, b).

It is not known if the abscission of turgid petals is preceded by cellular changes that are indicative of PCD. We therefore investigated the time line of some of these changes, in Prunus yedoensis and Delphinium belladonna. In both species the petals abscise without any visible sign of turgor loss. We used DNA degradation (measured both on agarose gels and by using flow cytometry), chromatin condensation, and a decrease in nuclear diameter as parameters that indicate PCD. According to our hypothesis these parameters would not detectably change, prior to petal abscission.

\section{Materials and methods}

Plant material

Plants were grown in the garden of National Institute of Floricultural Science of Japan (P. yedoensis cv. Someiyoshino) or the greenhouse of the institute (D. belladonna cv. Bellamosum, Ipomoea nil cv. Violet, and Petunia hybrida cv. Double Duo Pink). Just before the onset of flower opening, cut branches (P. yedoensis) or potted plants (the other species) were transferred into a growth chamber at $24 \pm 1{ }^{\circ} \mathrm{C}$, about $70 \%$ relative humidity (RH), and $12 \mathrm{~h}$ of daily illumination from cool-white fluorescent lights $\left(100 \mu \mathrm{mol} \mathrm{m}^{-2} \mathrm{~s}^{-1}\right)$. The time to petal abscission and petal desiccation was observed daily, on plant material in the growth chamber. The timing of these symptoms was noted in six flowers from two plants. All determinations were made using petals that were collected from plant material in the chamber.

\section{DNA degradation}

DNA breakdown was detected by agarose gel analysis. Total DNA was extracted according to Yamada et al. (2003). The amount of DNA was estimated by molecular absorption spectrophotometry. Equal amounts of total DNA $(3 \mu \mathrm{g})$ were immediately electrophoresed in a gel contain- ing 3\% agarose and stained with SYBR Gold nucleic acid gel stain (Molecular Probes, Eugene, OR, USA). The gel pattern was photographed, using an electronic UV transilluminator system (model FAS-III mini + DS-30; Toyobo, Tokyo, Japan). The DNA degradation index was calculated according to Yamada et al. (2006b).

Two biological replications, each containing several petals, were used for each stage of development. Depending on the species, two to several petals were used in each sample.

\section{Flow cytometry}

The petal was chopped in nuclear extraction buffer, part of the kit (High Resolution kit) for plant DNA analysis (Partec, Münster, Germany), a reagent set provided by the manufacturer of the flow cytometer used (Ploidy Analyzer, Partec). The extraction buffer in this kit was a low $\mathrm{pH}$ solution containing Triton X-100. The extract was filtered through $50 \mu \mathrm{m}$ nylon mesh. The medium with the isolated DNA masses (nuclei) was collected, the buffer with the fluorescent DNA stain 4, 6-diamidino-2-phenylindole (DAPI) from a standard reagent set (Partec) was added, and the solution was vortex mixed. The DNA content of the isolated nuclei was analysed using the flow cytometer. The flow cytometer apparatus can be set to count all nuclei in a sample, and can be set to analyse a fixed number of nuclei. We here set it to detect 5,000 nuclei. DNA levels were obtained in a total of 5,000 nuclei. It should be noted that the large histogram peak was adjusted to 10 on the fluorescence scale. This means that nuclear condensation was not taken into account in the flow cytometry data.

Two biological replications, each containing several petals, were used for each stage of development. Depending on the species, three to several petals were used in each sample. In each species, the number of petals was the same at all stages of development.

Nuclear morphology; chromatin condensation

Nuclei were isolated from petals in the same way as for flow cytometry. Isolated nuclei were stained with DAPI, which stains DNA. The nuclei were observed under a fluorescence microscope (model PROVIS AX70, Olympus, Tokyo, Japan) using U-excitation $(330-385 \mathrm{~nm})$. Digital photography of nuclei was obtained for each stain using low light cool CCD camera (model DP30BW, Olympus).

\section{Dehydration and ethylene treatment}

Flowers were excised when the petals were fully open. Cut flowers were placed in air in the growth chamber $\left(24^{\circ} \mathrm{C}\right.$, about $70 \% \mathrm{RH})$ or in a desiccator $\left(\right.$ at $\left.60^{\circ} \mathrm{C}\right)$. For ethylene 
treatments, stems of cut flowers were placed in sterile distilled water, in a closed 701 clear plastic box containing $2 \mu \mathrm{l} / \mathrm{l}$ ethylene. Petal abscission was checked at hourly intervals and abscised petals were collected immediately. The petals were then used instantly for the measurement of the various parameters mentioned.

\section{Statistics}

The number of replications is mentioned in the text and/or in the figure legends. Statistical analysis used one way analysis of variance, at $P<0.05$. All experiments were repeated at least once.

\section{Results}

Symptoms of petal life span cessation

P. yedoensis flowers have five pale pink petals. After flower opening the petals remained attached to the flower for about 4 days, and then fell without visible wilting (Fig. 1a, P2). During the first day following abscission, petals that were held at $24^{\circ} \mathrm{C}$ and $70 \% \mathrm{RH}$ changed colour from pale pink to darker pink, and subsequently became infiltrated with liquid (results not shown). By the end of the first day following abscission, the petals started to shrivel at their margins (Fig. 1a, P3). By the end of the second day after abscission the petals had much more decreased in size (Fig. 1a, P4). The stages 2-4 (pictures P2-P4) in Fig. 1a use the same scale thus show the decrease in petal size.
Flowers of Delphinium species contain five petals one of which has a large spur. The petals of D. belladonna fell about 7 days after flower opening (Fig. 1b, D2). They did not show any visible wilting symptom by the time of abscission. Two days after abscission the petals had slightly shrivelled (Fig. 1b, D3) but by day-3 after abscission the shrivelling had become very clear (Fig. 1b, D4). The stages 2-4 (pictures D2-D4) in Fig. 1b have the same scale.

\section{DNA degradation}

Figure 2 shows the petal DNA agarose gels of one of two repeat experiments. The pixel ratios under the lanes are the means of two experiments. In both species, the agarose gels showed no DNA fragments at the time of flower opening (Fig. 2, lanes P1 and D1). By the time of abscission, the petals of $P$. yedoensis did not show a statistically significant $(P<0.05)$ increase in DNA fragmentation, compared with the time of floral opening (Fig. 2, lane P2). In contrast, the petals of D. belladonna showed a considerable increase in DNA fragmentation by the time of abscission (Fig. 2b, lane D2, pixel intensity had increased from 4.3 to 17.4). Following petal abscission the degree of DNA fragmentation, as observed on agarose gels, increased in P. yedoensis (Fig. 2a, compare lane $\mathrm{P} 3$ with lane $\mathrm{P} 2$ ) and further increased in D. belladonna (Fig. 2b, compare lane D3 with lane D2). By the time of petal desiccation (P4 and D4) the amount of fragmented DNA had become considerably lower than at the previous stage investigated, when the abscised petal showed visible wilting and dehydration (Fig. 2).
Fig. 1 Petal abscission and petal dehydration in $P$. yedoensis, indicated by a $P(\mathbf{a})$ and $D$. belladonna, indicated $D(\mathbf{b})$. Cut branches of (P. yedoensis) and potted plants $(D$. belladonna) stood in a growth chamber $\left(24^{\circ} \mathrm{C}\right.$, about $\left.70 \% \mathrm{RH}\right)$. The time to abscission and to dehydration symptoms (in days from full flower opening) is shown in the left lower corner of the pictures $(n=6)$. Stages $P 1$ and $D 1$ : full flower opening; $P 2$ and $D 2$, petal abscission; $P 3$ and $D 3$, petals visibly dehydrated; $P 4$ and $D 4$, petals desiccated. All pictures have the same scale (bars $=10 \mathrm{~mm}$ )
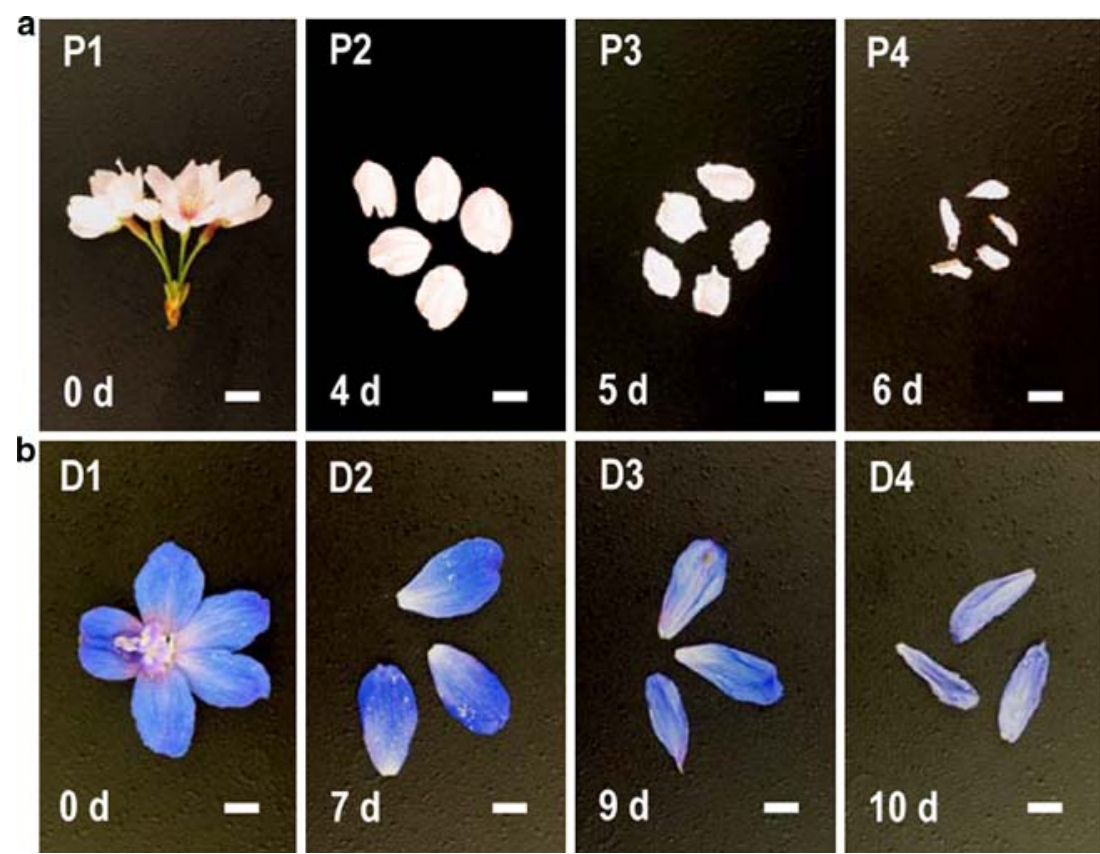
Fig. 2 Agarose gel analysis of total DNA isolated from the petals of $P$. yedoensis, annotated as $P(\mathbf{a})$ and $D$. belladonna, annotated as $D(\mathbf{b}) .3 \mu \mathrm{g}$ of total DNA was extracted from the petals and electrophoresed in a $3 \%$ agarose gel. Lanes $P 1-P 4$ and $S D 1-S D 4$ refer to DNA isolated from petals at stages $P 1-P 4$ and $D 1-D 4$ as shown in Fig. 1. Stages $P 1$ and $D 1$ : full flower opening; $P 2$ and $D 2$, petal abscission; $P 3$ and $D 3$, petals visibly dehydrated; $P 4$ and $D 4$, petals desiccated. Pixel ratios below the lanes are means of two repeat experiments

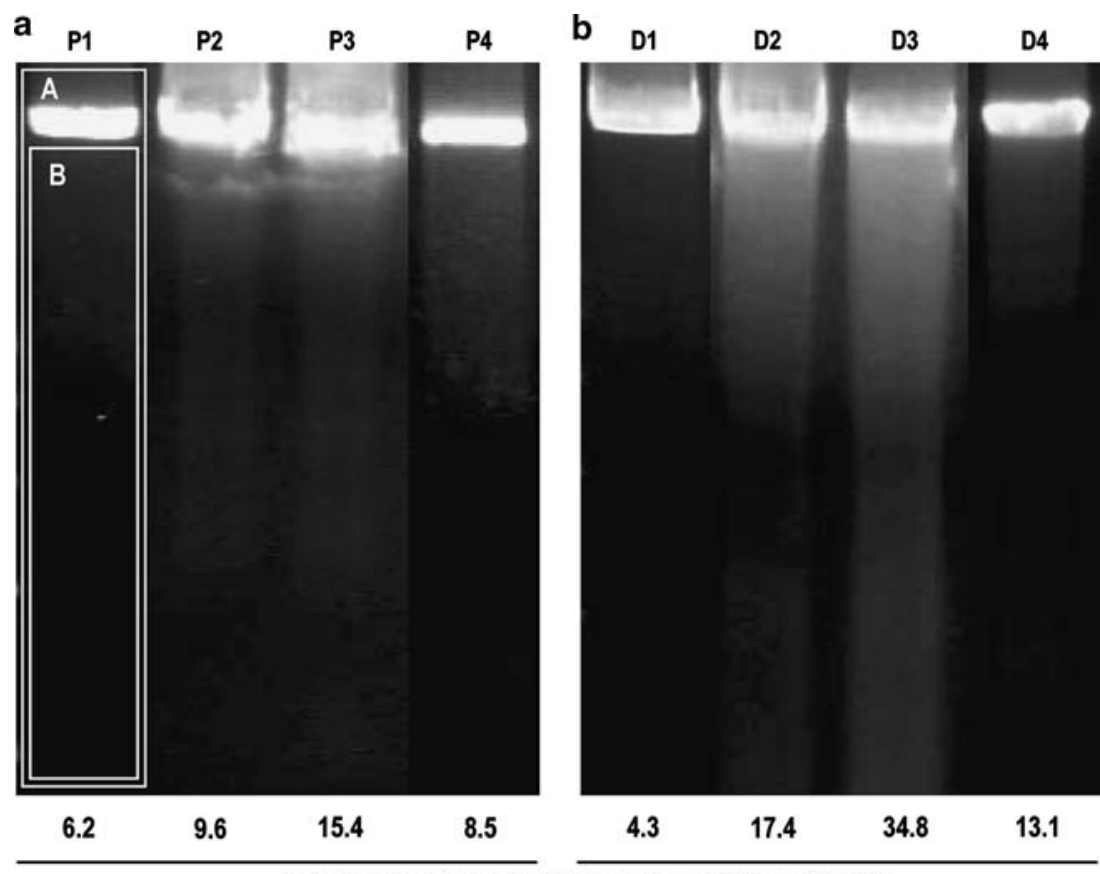

Relative pixel intensity between $A$ and $B$ ( $B$ as $\%$ of $A$ )
Nuclear morphology

In $P$. yedoensis petals the nuclear morphology had not clearly changed by the time of petal abscission (Fig. 3a). This is in contrast with $D$. belladonna where visual inspection showed that the nucleus was much smaller by the time of abscission, compared with the size observed at flower opening. The small nuclei of $D$. belladonna showed brighter DAPI fluorescence than the nuclei at flower opening. This indicates a high concentration of DNA per unit volume, thus chromatin condensation (Fig. 3b, D2). Nuclear morphology was studied using light microscopy, giving a two-dimensional impression only. For this reason nuclear size will be referred to as nuclear area.

After abscission, during the period of dehydration, the nuclei of both species showed an increase in area (Fig. 3) In P. yedoensis the nuclear area at stage P4 seemed even considerably larger than that at floral opening (Fig. 3a). In D. belladonna the nuclear area was apparently similar at D4 compared to the stage of floral opening (D1), but it was ostensibly much larger compared with the area at the stage of petal abscission (P2; Fig. 3b). In both species the nuclear periphery was no longer smooth at stage P4 or D4 (Fig. 3). In both species investigated, numerous nuclei showed the morphology shown in Fig. 3, stages P4 and D4. The area of the remaining nuclei did not increase as much, whilst a few nuclei had not changed in nuclear area with respect to controls at flower opening.
Flow cytometry of nuclei at various stages prior to and after abscission

Flow cytometry of nuclei stained for DNA (with DAPI) shows the distribution of nuclei in fluorescence classes. The $X$-axis in Fig. 4 is divided in numerous classes of increasing fluorescence, and the $Y$-axis shows the number of nuclei per fluorescence class. Flow cytometry of 5.000 petal nuclei at the time of $P$. yedoensis flower opening showed a peak of nuclei at phase G0/G1 (which was set at $10^{1}$ on the arbitrary logarithmic scale of the $X$-axis), and no mitotic nuclei (G2/ $\mathrm{M})$, which have a fluorescence about two times that of normal G0/G1 nuclei. By the time of petal abscission, no change had occurred in the DNA fluorescence histogram (Fig. 4a, P2). Two days after abscission, the height of the G0/G1 peak had diminished but the peak had not shifted. This is shown by mixing nuclei from day-0 to -6 (Fig. 4a, P1 + P4). The data suggest that a small amount of DNA had become degraded by day- 2 after abscission.

By the time of petal abscission in D. belladonna, flow cytometry revealed a decrease in the height of the G0/G1 phase nuclei, and several nuclei with a fluorescence less than that of G0/G1 phase nuclei (Fig. 4b, D2). During the 3 days following abscission the G0/G1 peak height further decreased and the number of nuclei with fluorescence lower than G0/G1 further increased. No clear shift in the G0/G1 peak was observed: a mix of nuclei at day-0 and -10 did not result in a bimodal curve (Fig. $4 b, \mathrm{D} 1+\mathrm{D} 4)$. The results indicate extensive DNA degradation, before, during, and after abscission. 

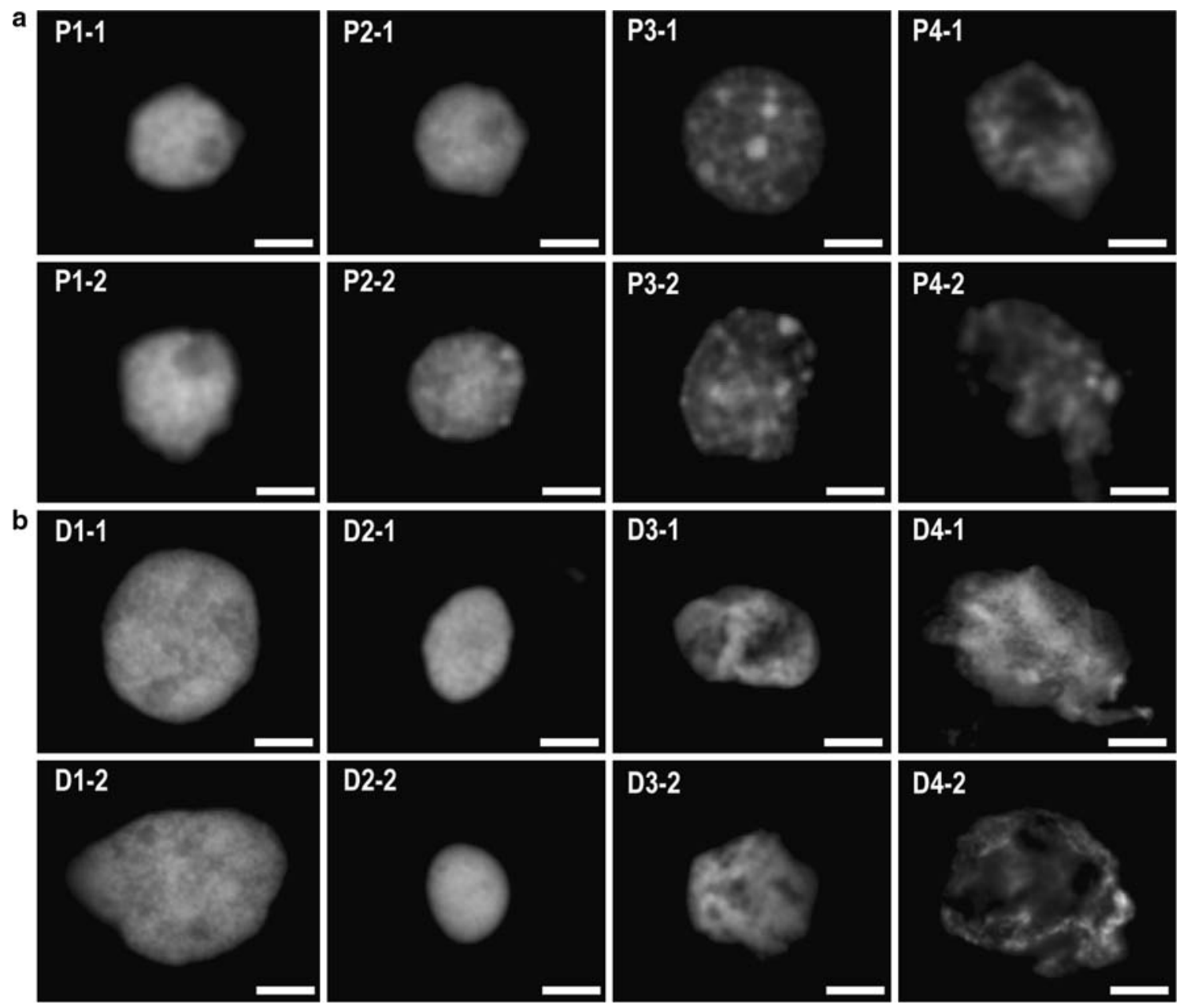

Fig. 3 Morphology of DAPI-stained nuclei in the petals of $P$. yedoensis, indicated by a $P(\mathbf{a})$ and $D$. belladonna, indicated $D(\mathbf{b})$. Two representative nuclei ( -1 and -2$)$ are shown at each stage of development.

microscope under U-excitation. Bars: $5 \mu \mathrm{m}$ (a) or $15 \mu \mathrm{m}$ (b). Stages as in Fig 1. $P 1$ and $D 1$ 1: full flower opening; $P 2$ and $D 2$, petal abscission; $P 3$ and $D 3$, petals visibly dehydrated; $P 4$ and $D 4$, petals desiccated Nuclei were isolated from the petals and observed using a fluorescence

Fig. 4 Fluorescence of DAPIstained nuclei. Histograms were obtained by flow cytometry of 5,000 nuclei isolated from the petals of $P$. yedoensis (indicated by a $P$ ) as shown in $\mathbf{a}$, and petals of $D$. belladonna $(D)$ shown in b. Petals were severed from cut twigs placed in water (Prunus) or potted plants (Delphinium), which stood both in a growth chamber $\left(24^{\circ} \mathrm{C}\right.$, about $\left.70 \% \mathrm{RH}\right)$. Stages as in Fig. 1. $P 1$ and $D 1$ : full flower opening; $P 2$ and $D 2$, petal abscission; $P 3$ and $D 3$, petals visibly dehydrated; $P 4$ and $D 4$, petals desiccated
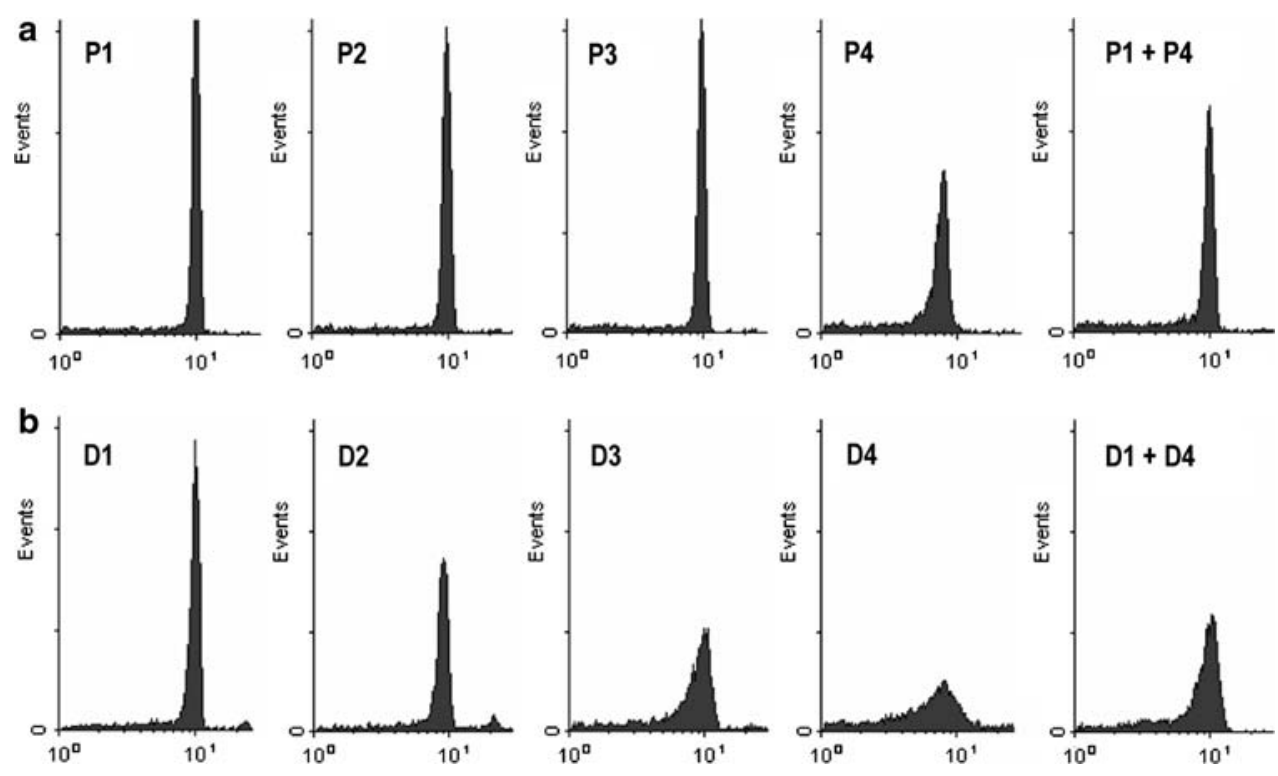


\section{Effects of ethylene}

Ethylene treatment greatly hastened the time to petal abscission, in both species (Fig. 5a, compared with Fig. 1a). In both species, the rate of petal dehydration after abscission was not much affected by the ethylene treatment (Fig. 5a) compared with the control without ethylene (Fig. 1a). For example, 3 days after petal fall in $D$. belladonna the petals had extensively shrivelled, independent of the time of petal fall (day-7 in controls and day-2 in ethylene-treated flowers).

In both species, flow cytometry revealed no effect of ethylene treatment on DNA fluorescence at the time of petal fall, compared to the fluorescence at the time of flower opening (Fig. 5b). After petal fall, a clear shift to lower DNA fluorescence of the G0/G1 peak of fluorescence was observed in P. yedoensis (Fig. 5b, upper sequence), which was not found in controls without ethylene treatment (Fig. 4, upper sequence). A small shift to lower DNA fluorescence (Fig. 5b, lower sequence), also not found in controls (Fig. 4 lower sequence), was also observed after ethylene treatment of $D$. belladonna. Superimposition of the stages P1 and EP4 (control and ethylene-treated stage 4 of $P$. yedoensis) showed two peaks of DNA fluorescence (Fig. 5b, upper sequence). A similar tendency was observed
Fig. 5 Effect of ethylene on petal abscission and DNA fluorescence of nuclei in the petals of $P$. yedoensis and D. belladonna. Time to petal abscission and petal dehydration symptoms (a) and flow cytometric determination of 5,000 DAPI-stained nuclei (b) of ethylene-treated branches of $P$. yedoensis and potted plants of $D$. belladonna. Ethylene treatment is annotated by $E$. Compare stages of development with untreated controls shown in Fig. 1, and with fluorescence data of controls in Fig.4. The left lower corner of the pictures series a show the times to abscission (EP2 and $E D 2)$ and the time to dehydration symptoms (both expressed in days from full flower opening; $n=6)$. Stages $P 1$ and $D 1$ : full flower opening; $E P 2$ and $E D 2$, petal abscission; $E P 3$ and $E D 3$, onset of petal dehydration; $E P 4$ and $E D 4$, petals desiccated. All pictures have the same scale (bars $=10 \mathrm{~mm}$ )
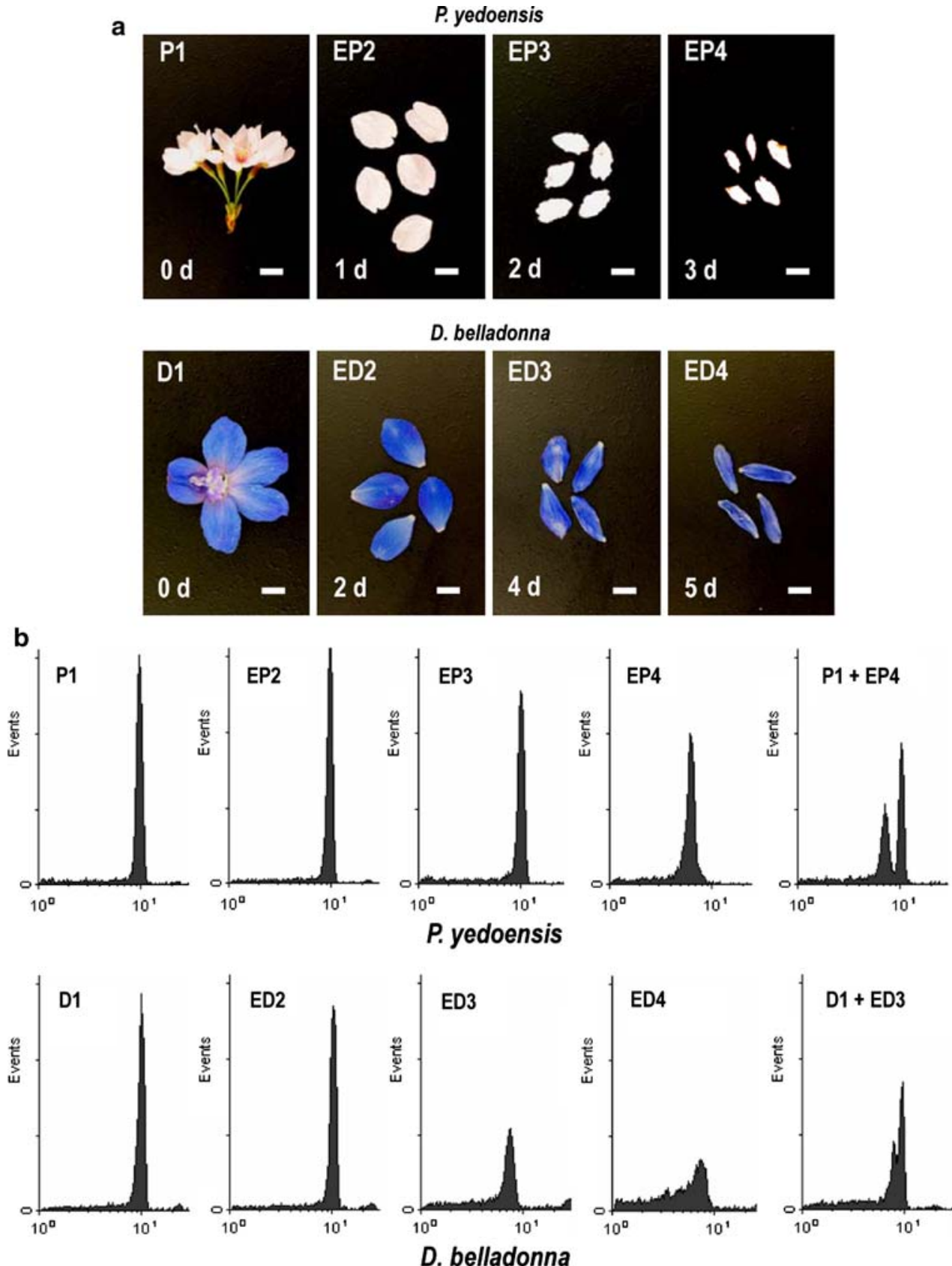
by superimposing the stages D1 and ED3 (Fig. 5b, lower sequence).

\section{Dehydration of petals cut at flower opening}

Flowers were harvested just after opening and subjected to a dehydration treatment at $60^{\circ} \mathrm{C}$ for $24 \mathrm{~h}$. The treatment resulted in a petal FW of about $20 \%$ of that of controls. Preliminary experiments showed that such a treatment resulted in a decrease of FW, and in changes of other parameters such as DNA degradation and nuclear morphology, that were very similar to dehydration on the laboratory bench (about $20^{\circ} \mathrm{C}$ and $70 \% \mathrm{RH}$ ) for about $96 \mathrm{~h}$.

Treatment of $P$. yedoensis flowers at $60^{\circ} \mathrm{C}$ for $24 \mathrm{~h}$ (Fig. 6a, DP) resulted in a slight increase in petal DNA degradation, as shown on agarose gel (Fig. 6b, DP). In contrast, this treatment induced a large increase in DNA degradation in D. belladonna petals (Fig. 6b, DD).

The dehydration treatment also had a small effect on DNA fluorescence of nuclei from $P$. yedoensis petals
Fig. 6 Effect of dehydration on DNA degradation, DNA fluorescence of nuclei, and nuclear morphology in the petals of $P$. yedoensis $(P)$ and D. belladonna $(D)$. Dehydration in the two species is indicated as $D P$ and $D D$, respectively. a Flower morphology before $(P 1$ and $D 1)$ and after $(D P$ and $D D)$ dehydration at $60^{\circ} \mathrm{C}$ for $24 \mathrm{~h}$. Photographs show small branches with fully opened flowers and desiccated flowers of $P$. yedoensis $(P 1$ and $D P)$ and the same for individual flowers of $D$. belladonna $(D 1$ and $D D)$. All pictures have the same scale (bars $=10 \mathrm{~mm}$ ). b Agarose gel analysis of total DNA isolated from the petals. c Flow cytometric determination of nuclei isolated from the petals. $\mathbf{d}$

Morphology of nuclei in the petals. Two representative nuclei (1 and -2) are shown for each species, after the dehydration treatment $(D P$ and $D D)$. Bars $=5 \mu \mathrm{m}$ $(P 1$ and $D P)$ or $15 \mu \mathrm{m}(D 1$ and $D D)$ a

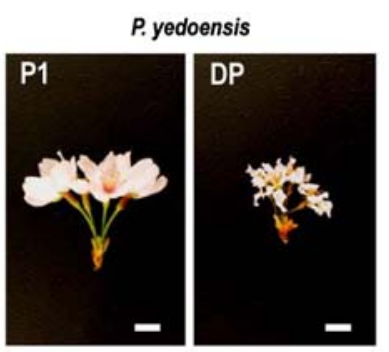

D. belladonna
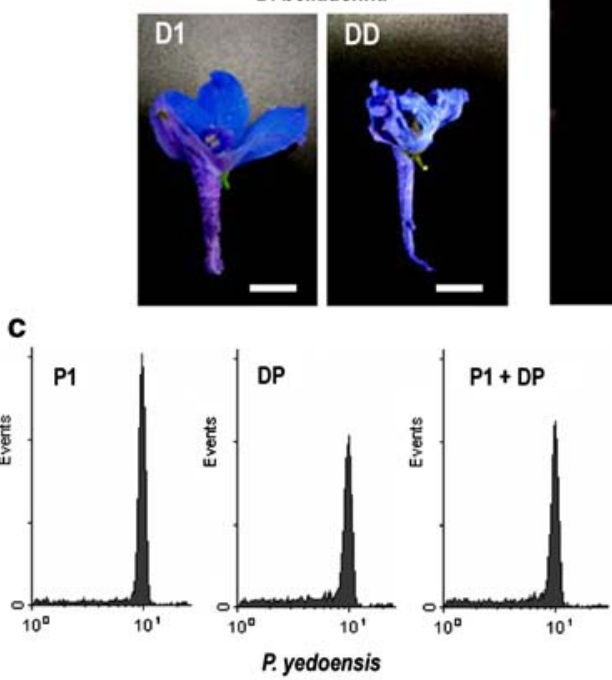

d
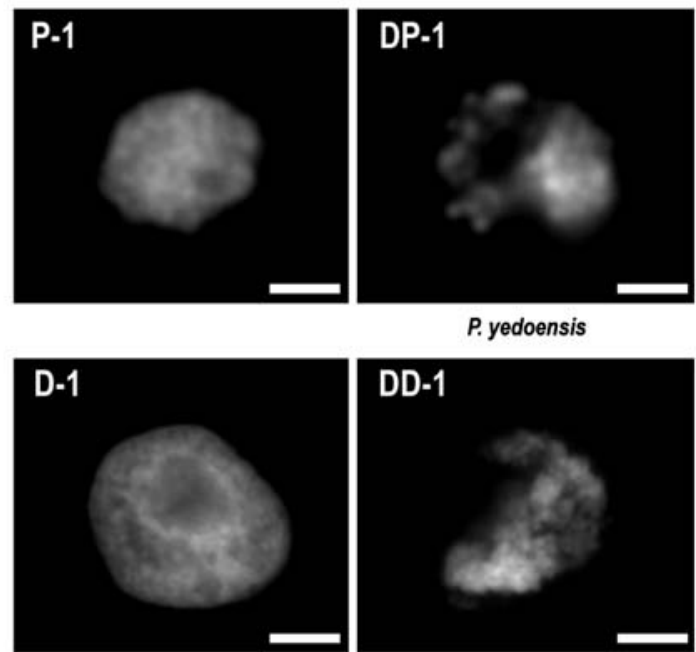
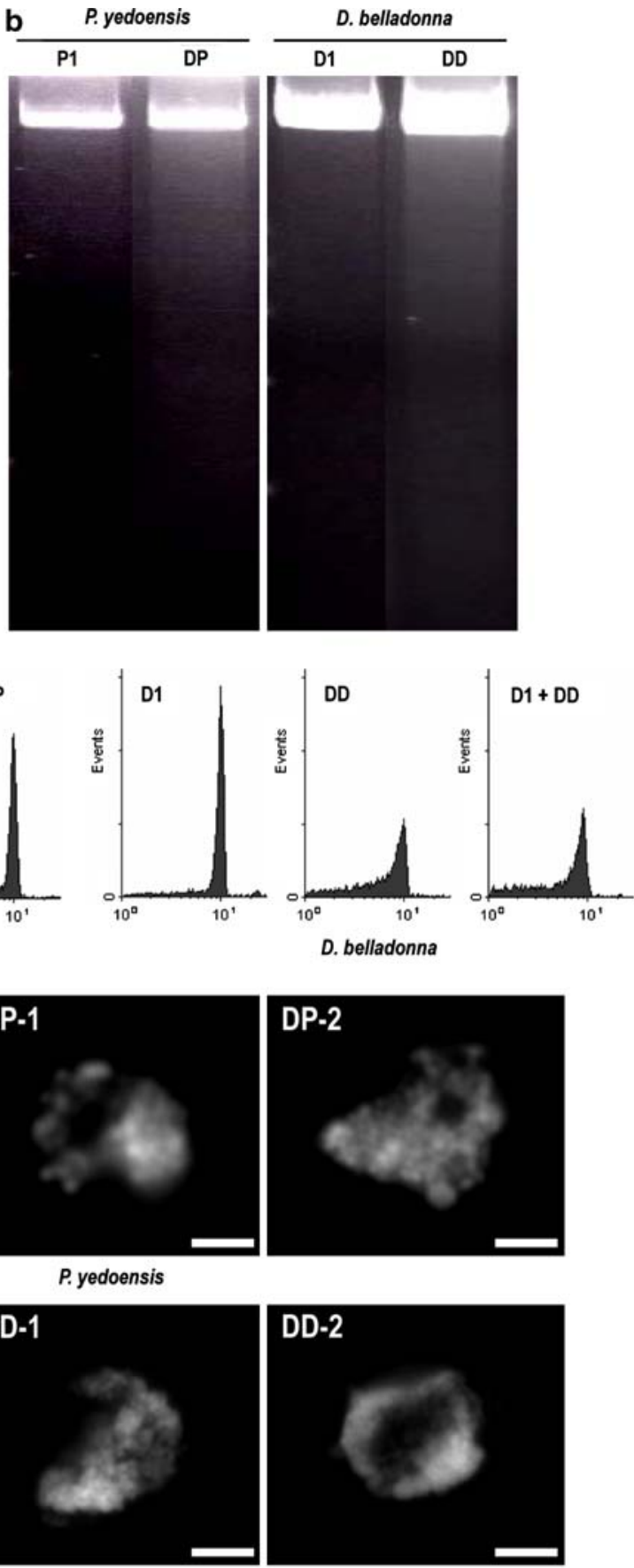

D. belladonna 
(Fig. 6c). Superimposition of the nuclei prior to and after treatment showed no shift to lower DNA fluorescence (Fig. 6c, P1 + DP). In D. belladonna, the dehydration treatment resulted in lower G0/G1 DNA fluorescence, and many nuclei with a lower than G0/G1 fluorescence (Fig. 6c). Superposition of the treatment and the control showed no shift of the G0/G1 peak of DNA fluorescence (Fig. 6c, D1 + DD).

Following the dehydration treatment, the nuclei of $P$. yedoensis had apparently somewhat increased in area, but no clear increase in nuclear area was discernable in $D$. belladonna (Fig. 6d). The chromatin distribution in the nuclei, after the dehydration treatment (Fig. 6d) was similar to that after dehydration due to abscission (Fig. 3). Visual inspection indicated that about $80 \%$ of all nuclei had the morphology shown in Fig. 6c, d. The area of the remaining nuclei had not as much increased.

\section{Dehydration of petals in species that show petal wilting} (Ipomoea and Petunia)

Similar dehydration treatments $\left(60^{\circ} \mathrm{C}\right.$ for $\left.24 \mathrm{~h}\right)$ were carried out with $I$. nil and Petunia hybrida, species in which the petals wilt by the end of flower life span. Wilting is shown as inrolling in $\mathrm{I}$. nil, which occurs at about $12 \mathrm{~h}$ after flower opening, in plants held at $24^{\circ} \mathrm{C}$ (Fig. 7a). Wilting is observed after 7 days at $24^{\circ} \mathrm{C}$ in flowers attached to $P$. hybrida plants (Fig. 7a).

Flowers were detached from potted plants, just after full opening. Fig. $7 \mathrm{~b}$ shows considerable DNA fragmentation on agarose gels, after the dehydration treatment $\left(60^{\circ} \mathrm{C}\right.$ for $24 \mathrm{~h}$ ), in both species tested. Flow cytometry of Ipomoea petals held at $60^{\circ} \mathrm{C}$ for $24 \mathrm{~h}$ showed a large decrease in DNA fluorescence, compared to controls of Ipomoea (Ip) before desiccation (Fig. 7c, compare DIp with Ip, whereby D means dehydrated). Fig. 7d shows that DNA degradation was also found in Petunia (Pe). Superimposition of the fluorescence in controls and the treated samples showed two peaks (Fig. 7c, d).

The morphology of DAPI-stained nuclei of $I$. nil and $P$. hybrida, after petal desiccation at $60^{\circ} \mathrm{C}$ for $24 \mathrm{~h}$, is shown in Fig. 8. Compared to nuclei of petals in flowers that had just fully opened (two panels upper left), relatively large parts not stained with DAPI were observed (two panels upper right). In $I$. nil the nuclear area had not become clearly increased, compared to those in petals that had not been desiccated (Fig. 8a), but inflated nuclei were observed in $P$. hybrida (Fig. 8b). Visual inspection indicated that about $80 \%$ of all nuclei showed the morphology shown in Fig. 8b. The area of the remaining nuclei had not as much increased.

Both in I. nil (Fig. 8a, S1-S4) and in P. hybrida (Fig. 8b, $\mathrm{S} 1-\mathrm{S} 4)$ the nuclear morphology after the dehydration
Fig. 7 Effect of dehydration on fresh weight, DNA degradation, and DNA fluorescence of nuclei in the petals of $I$. nil and $P$. hybrida. Potted plants were grown in a greenhouse and then placed in a climate-controlled chamber $\left(24^{\circ} \mathrm{C}\right.$, about $\left.70 \% \mathrm{RH}\right)$. Petals were detached from flowers that had just opened, and were placed at $60^{\circ} \mathrm{C}$ for $24 \mathrm{~h}$ to dehydrate. In a the time until about half of each petal had wilted (in days from full flower opening; $n=6$ ) is shown in the left lower corner of the pictures. a Morphology of the flowers, at opening (left) and at petal wilting (right). All pictures have the same scale (bars $=10 \mathrm{~mm}$ ). b Agarose gel analysis of total DNA isolated from the petals. c, $\mathbf{d}$ Flow cytometric determination of 5,000 $D A P I$-stained nuclei isolated from the petals of $I$. nil (c) and $P$. hybrida (d). Ip, Ipomoea; $P e$, Petunia, $D$, dehydration a
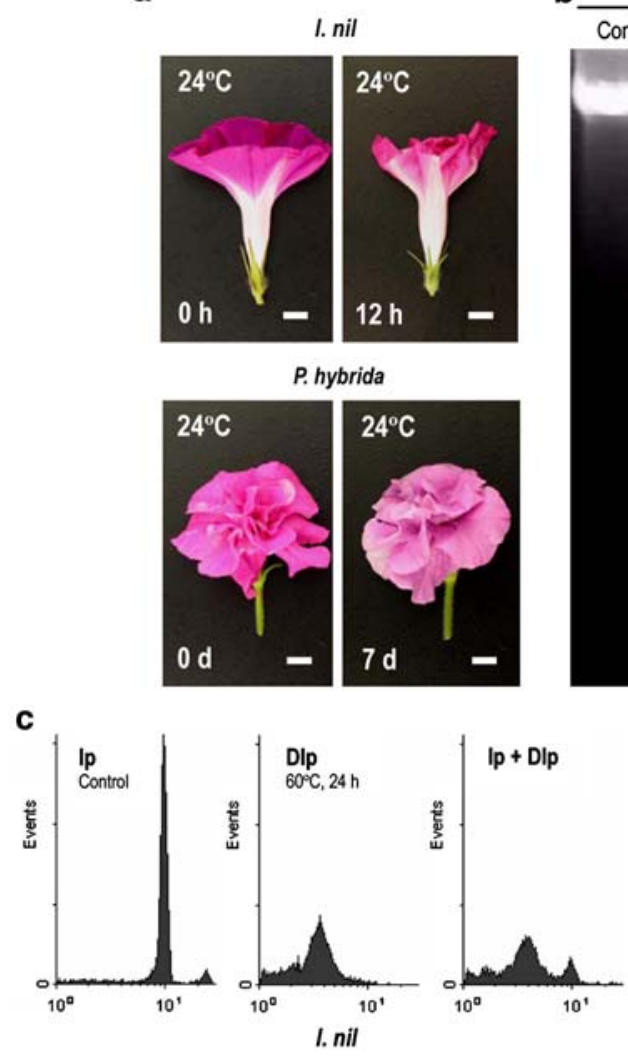

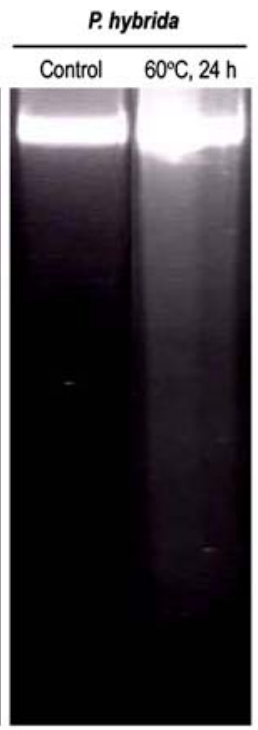

d
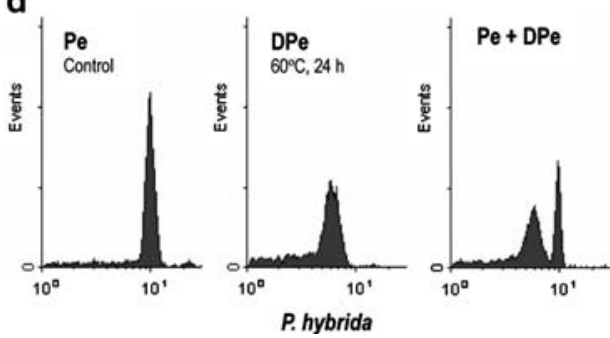

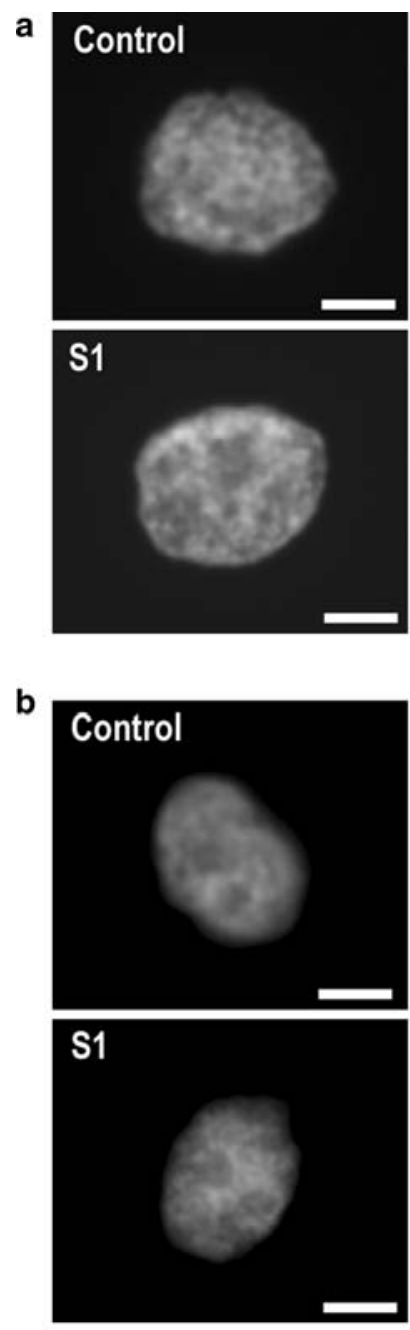
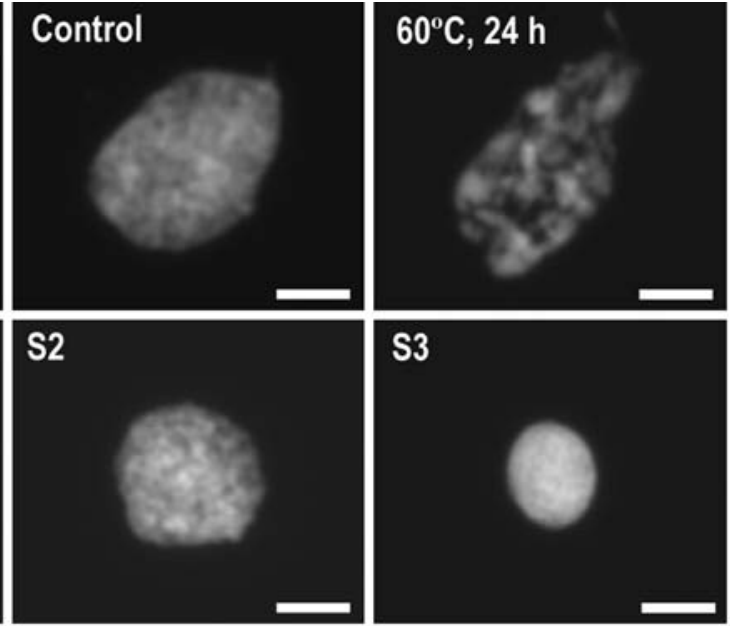

I. nil
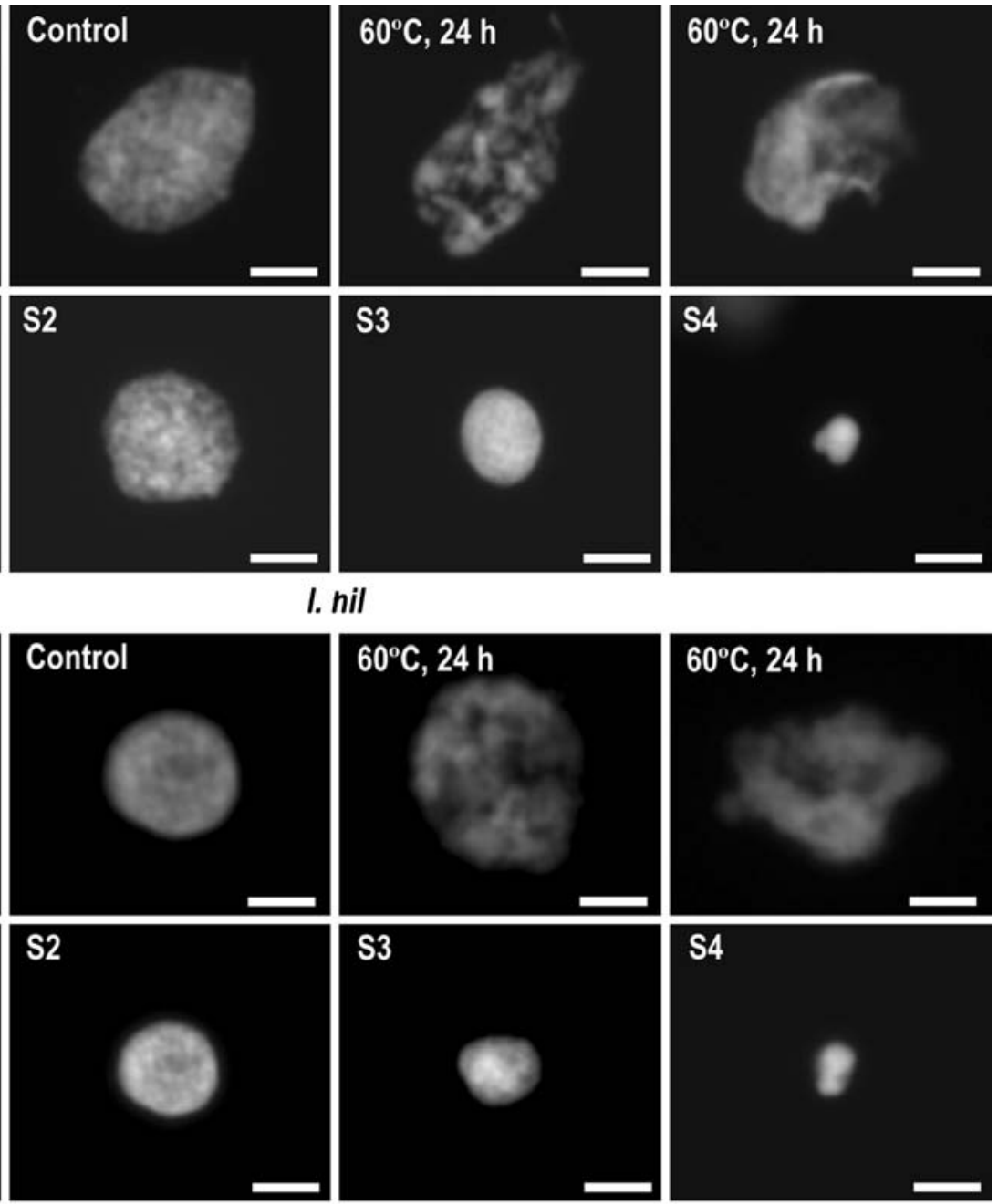

\section{P. hybrida}

Fig. 8 Effect of dehydration on nuclear morphology in the petals of I. nil and P. hybrida. Nuclei were isolated from the petals of $I$. nil (a) and $P$. hybrida (b) after the indicated treatments, then observed using a fluorescence microscope under U-excitation. For comparison, the nuclei are shown during PCD of petals that remained attached to the

treatment was quite different from the one observed during normal PCD. During PCD of petals that remained attached to the plant the area of the nuclei became increasingly smaller, whereas the brightness of DNA fluorescence remained high at least until the nuclei had become quite small.

\section{Discussion}

In reports on animal cells the suggestion that PCD occurs is usually backed up by showing changes such as phosphatidylserine externalization to the outer leaflet of the plasma membrane, caspase activation, and DNA degradation. Only the addition of a number of such parameters seems indicative of PCD. In the present study we took massive DNA plant (for data of Ipomoea and Petunia see also Yamada et al. 2006a, b). Stage $S 1$ : full flower opening; $S 2$ : onset of petal wilting; $S 3$ : full petal wilting; and $S 4$ : petals desiccated but still attached to the flower. Bars $=10(\mu \mathrm{m}$

degradation (measured in two ways), chromatin condensation, and a decrease in nuclear diameter as indicators of PCD. In other studies on petal PCD, it was shown that these parameters were each correlated with other indicators of PCD and also correlated with visible PCD symptoms such as petal wilting (Yamada et al. 2003, 2006a, b). We therefore suggest that these parameters, which separately represent only circumstantial evidence for PCD, are, when occurring together, adequate to indicate PCD.

We hypothesized that PCD parameters will not show in petal cells, prior to the abscission of turgid petals. The results of $D$. belladonna petals contradict the hypothesis, while those of $P$. yedoensis are in agreement with it. The data suggest that the degree of PCD, prior to abscission of turgid petals, depends on the species. The present data indicate that abscission of fully turgid petals may coincide with 
an advanced stage of PCD in many petal cells. The absence of visible wilting in abscising petals, therefore, does not seem to show absence of PCD. This is so because the wilting that is often associated with PCD is quite a late stage in the PCD process.

In petals the timing of PCD and that of abscission may be regulated independently. Independent regulation would explain the large variation of their relative timing, among the Angiosperms. In many species PCD comes much earlier than abscission (species showing petal wilting at the end of floral life), whereas in other species abscission comes first. In most species in which floral life span is ended by petal wilting, the petals eventually abscise, even when most of the petal surface has become desiccated. In these species the petal base, where abscission takes place, remains alive. Only in a few species fully desiccated petals are torn-off by the growing fruit, or (in still other species) remain attached to the fruit (van Doorn and Stead 1997; van Doorn 2001).

The agarose gel data (Fig. 2) showed substantial DNA degradation prior to and during abscission in $D$. belladonna and less DNA degradation prior to and during petal fall in $P$. yedoensis. Flow cytometry data (Fig. 4) confirmed the agarose gel data. DNA degradation seems a relatively late PCD process. Mass protein degradation, a late process, may serve as a yardstick. In Ipomoea petals, bulk degradation of proteins and DNA occurred at about the same time (Winkenbach 1970a, b). In Iris petals, $40 \%$ of total DNA had become degraded (van der Kop et al. 2003) by the time of the onset of mass protein degradation (Pak and van Doorn 2005). In Alstroemeria petals DNA breakdown (Wagstaff et al. 2003) started slightly before the decrease in protein content (Wagstaff et al. 2002).

When using agarose gels to show DNA breakdown during PCD, a ladder of DNA fragments is often observed, at least in association with apoptosis in animal cells. DNA laddering on gels is the result of oligonucleosomal cleavage, resulting in DNA sequences of multiples of about $180 \mathrm{bp}$. In contrast to apoptosis in animal cells, the DNA breakdown pattern during plant PCD is quite variable and depends on the system. For example, during petal PCD clear DNA laddering without a background of DNA fragments of various lengths is rarely found. Most reports show DNA laddering against a background of fragments of various lengths (Orzáez and Granell 1997; Wagstaff et al. 2003; Yamada et al. 2003) or only fragments of various lengths (van der Kop et al. 2003). The present results fall in the last category.

Nuclear morphology at the time of petal abscission also suggested advanced PCD in the petal cells of $D$. belladonna and little PCD in those of $P$. yedoensis. The nuclei of $D$. belladonna were much smaller and showed bright DAPI fluorescence, indicating chromatin condensation. No chromatin condensation was observed in $P$. yedoensis petals, but here it might possibly have occurred between the stages P2 and P3 and therefore may have been missed. We found that most but not all nuclei underwent the changes shown at the stages $2-4$ of Fig. 3. The difference might relate to differences in PCD progress, within the petal. It is known that cells associated with the vascular bundle undergo PCD at a later stage than the other petal cells. In some species the mesophyll cells also show earlier PCD than the epidermis cells (van Doorn et al. 2003).

Little is known about the physiology of petal cells, after abscission. The cells of abscised petals, as long as they remain alive, will be subject to a considerable decrease in water potential. Using young detached corollas (petals) of Ipomoea flowers, we observed that $\mathrm{FW}$ was about $65 \%$ of initial after $24 \mathrm{~h}$ on the laboratory bench (at about $20^{\circ} \mathrm{C}$ and $70 \% \mathrm{RH}$ ) and $50 \%$ of initial after $48 \mathrm{~h}$ (unpublished data). This indicated that some physiological processes would occur at least during day- 1 and -2 , but that these processes would be influenced by lower water potential.

Both agarose gel (Fig. 2, P3 and D3) and flow cytometry analysis (Fig. 4) showed DNA degradation after the petals had abscised. The data indicate that the PCD process, once started, goes on even under conditions of increasing water stress. However, by the time of total desiccation of the petals, the amount of degraded DNA on gels was smaller than at the time of visible petal wilting of the abscised petals (Fig. 2, P4 and D4). This indicated that the DNA breakdown became halted by that time. This could be due to the fact that there was no more DNA, or might relate to the very low water potential in the tissue.

After petal abscission, the petal nuclei unexpectedly increased in size. In both species the chromatin became unevenly distributed. The chromatin became also much less condensed, as indicated by decreasing DAPI brightness. The increase in nuclear size and uneven and reduced DAPI brightness were also observed after dehydration of young $D$. belladonna and $P$. yedoensis petals. In these experiments flowers were cut from the plant just after floral opening and then subjected to a desiccation treatment $\left(24 \mathrm{~h}\right.$ at $\left.60^{\circ} \mathrm{C}\right)$. This treatment, apart from inducing dehydration, also involved an increase in temperature. The effects did not seem to be due to high temperature though, as preliminary experiments had shown that $72-96 \mathrm{~h}$ desiccation at room temperature had the same effects as $24 \mathrm{~h}$ treatment at $60^{\circ} \mathrm{C}$. This indicates that the effect was due to dehydration rather than high temperature, and that it was not only taking place in cells that were relatively old, but also in much younger cells.

I. nil and P. hybrida flowers both exhibit petal wilting rather than abscission at the end of floral life span. An increase in nuclear volume and a decrease in DAPI brightness were also found in the nuclei, if the flowers of these species were severed when just fully open and then subjection 
to a $24 \mathrm{~h} 60^{\circ} \mathrm{C}$ desiccation treatment. Preliminary experiments with these species had also shown that 72-96 h desiccation at room temperature had the same effects as $24 \mathrm{~h}$ treatment at $60^{\circ} \mathrm{C}$. These results indicate that the particular nuclear morphology observed after dehydration in $P$. yedoensis and $D$. belladonna is also found in the petals of other species, which show petal wilting rather than petal abscission at the end of flower life. The particular nuclear morphology, therefore, seemed related to the low water potential as a result of the dehydration treatment. After the dehydration treatment in I. nil or P. hybrida the nuclear morphology was quite different from the one observed during wilting as the final phase of PCD. At the time of the normal senescence-related petal wilting in Ipomoea (Yamada et al. 2006b) and Petunia (Yamada et al. 2006a) flowers, the nuclei had become much smaller than at previous phases of development, and had a rather bright DAPI fluorescence. The desiccation treatment, therefore, induced changes quite different from those observed during PCD: a large nucleus with faint DAPI fluorescence rather than a small one with bright fluorescence.

It is concluded that the tested parameters indicated advanced stages of PCD prior to petal abscission in D. belladonna whereas PCD was much less obvious by the time of petal abscission in $P$. yedoensis. Dehydration of the petal cells, after abscission, was associated with a remarkable change in nuclear morphology and chromatin distribution. Similar changes in the nucleus were found after dehydration of younger petal cells, and after dehydration of the petal cells in two other species. This nuclear morphology has apparently not been described previously.

Acknowledgments The work was supported by a grant of the Japan Society for the Promotion of Science, (JSPS, grant number S-04139), allowing the corresponding author to work in Japan.

\section{References}

Gunawardena AHLAN, Pearce DM, Jackson MB, Hawes CR, Evans DE (2001) Characterisation of programmed cell death during aerenchyma formation induced by ethylene or hypoxia in roots of maize (Zea mays L.). Planta 212:205-214
Orzáez D, Granell A (1997) The plant homologue of the defender against apoptotic death gene is down-regulated during senescence of flower petals. FEBS Lett 404:275-278

Pak C, van Doorn WG (2005) Delay of Iris flower senescence by protease inhibitors. New Phytol 165:473-480

van der Kop DAM., Ruys G, Dees D, van der Schoot C, de Boer AD, van Doorn WG (2003) Expression of defender against apoptotic death (DAD-1) in Iris and Dianthus petals. Physiol Plant 117:256-263

van Doorn WG (2001) Categories of petal senescence and abscission: a re-evaluation. Ann Bot 87:447-456

van Doorn WG, Stead AD (1997) Abscission of flowers and floral parts. J Exp Bot 48:821-837

van Doorn WG, Balk PA, van Houwelingen AM, Hoeberichts FA, Hall RD, Vorst O, van der Schoot C, van Wordragen MF (2003) Gene expression during anthesis and senescence in Iris flowers. Plant Mol Biol 53:845-863

Wagstaff C, Leverentz MK, Griffiths G, Thomas B, Chanasut U, Stead AD, Rogers HJ (2002) Cysteine protease gene expression and proteolytic activity during senescence of Alstroemeria petals. J Exp Bot 53:233-240

Wagstaff C, Malcolm P, Rafiq A, Leverentz M, Griffiths G, Thomas B, Stead AD, Rogers H (2003) Programmed cell death (PCD) processes begin extremely early in Alstroemeria petal senescence. New Phytol 160:49-59

Winkenbach F (1970a) Zum Stoffwechsel der aufblühenden und welkenden Korolle der Prunkwinde Ipomoea purpura I. Beziehungen zwischen Gestaltwandel, Stoffstansport, Atmung, und Invertaseaktivität. Berichte der Schweizerischen Botanischen Gesellschaft 80:374-390

Winkenbach F (1970b) Zum Stoffwechsel der aufblühenden und welkenden Korolle der Prunkwinde. Ipomoea purpurea. II Funktion und de novo Synthese lysosomaler Enzyme beim Welken. Berichte der schweizerischen botanischen Gesellschaft 80:391-406

Wojciechowska M, Olszewska MJ (2003) Endosperm degradation during seed development of Echinocystis lobata (Cucurbitaceae) as a manifestation of programmed cell death (PCD) in plants. Folia Histochem Cytobiol 41:41-50

Yamada T, Takatsu Y, Manabe T, Kasumi M, Marubashi W (2003) Suppressive effect of trehalose on apoptotic cell death leading to petal senescence in ethylene-insensitive flowers of Gladiolus. Plant Sci 164:213-221

Yamada T, Ichimura K, van Doorn WG (2006a) DNA degradation and nuclear degeneration during programmed cell death in petals of Antirrhinum, Argyranthemum, and Petunia. J Exp Bot 57:35433552

Yamada T, Takatsu Y, Kasumi M, Ichimura K, van Doorn WG (2006b) Nuclear fragmentation and DNA degradation during programmed cell death in petals of morning glory (Ipomoea nil). Planta 224:279-1290 